Vol. 11 No. 012020

e-issn : 2622-0148, p-issn : 2087-0035

\title{
EFEKTIFITAS SENAM AEROBIK PADA WANITA USIA SUBUR TERHADAP KESEIMBANGAN IMT DI DESA SENTUL KABUPATEN JOMBANG
}

Effectiveness of aerobic in a fertilizer women to body mass index balance in sentul village, jombang district

\author{
Fitri Firranda Nurmalisyah ${ }^{1}$, Zuliani $^{2}$ \\ 1Sekolah Tinggi llmu Kesehatan Pemkab Jombang \\ 2Universitas Pesantren Tinggi Darul Ulum (UNIPDU) Jombang \\ *) fitri@stikespemkabjombang.ac.id
}

\begin{abstract}
Physical inactivity is a term for identifying people with low levels of regular physical activity, or none at all. The imbalance between calories that enter through food and drinks with the burning of calories by physical activity makes the body a positive balance due to glucose and blood fat increases and weight gain. As a result, the energy combustion is not more than 1.5 times the energy burning when at rest. The purpose of this study was to determine the Effectiveness of Aerobic Gymnastics in Fertile Age Women on IMT Balance in Sentul Village, Jombang District. In this study, the type of research used was a pre-experimental study with one-group pretest-posttest design. This design also has no comparison group (control), but at least the first observation (pre-test) has been done which allows researchers to test changes that occur after an experiment (program) with a sample of 30 people. From the calculation using the application, it was obtained Z score $-3.742>Z$ table -1.96 . Asymp sig. Value (2 failed) or probability value $p=(0,000)$ is lower than the significant standard $\alpha=0.05$ or $(p<\alpha)$ which means $H 0$ is rejected which means there is a change in BMI in a fertilizer women after aerobic exercise. Aerobic exercise is effective against normal BMI in a fertilizer women in Sentul Village, Jombang Regency.
\end{abstract}

Keywords : aerobic, body mass index, fertilizer women

\section{ABSTRAK}

Ketidakaktifan fisik merupakan seseorang yang memiliki aktivitas fisik yang kurang atau tidak melakukan aktvitas fisik sama sekali. Hal ini dapat menimbulkan positive balance dimana ketidakseimbangan kalori yang masuk melalui makanan dan minuman dengan pembakaran kalori oleh aktivitas fisik tubuh yang mengakibatkan glukosa dan lemak darah meningkat serta berat badan naik. Hal ini mengakibatkan pembakaran energinya menjadi tidak lebih dari 1,5 kali pembakaran energi saat beristirahat. Tujuan penelitian ini adalah untuk mengetahui efektifitas senam aerobik pada wanita usia subur terhadap keseimbangan IMT di Desa Sentul Kecamatan Ploso Kabupaten Jombang. Dalam penelitian ini jenis penelitian yang di gunakan adalah penelitian pra eksperimental dengan rancangan one-group pretest-posttest design. Rancangan ini juga tidak ada kelompok pembanding (control), tetapi paling tidak sudah dilakukan observasi pertama (pre-test) yang memungkinkan peneliti dapat menguji perubahan-perubahan yang terjadi setelah adanya eksperimen (program) dengan sampel sebanyak 30 orang. Dari hasil perhitungan menggunakan aplikasi didapatkan $Z$ hitung $-3,742>Z$ tabel $-1,96$. Nilai asymp sig.(2 failed) atau nilai probabilitas $\mathrm{p}=(0,000)$ lebih rendah dari standart signifikan $\mathrm{a}=0,05$ atau $(\mathrm{p}<\mathrm{a})$ yang berarti $\mathrm{H}_{0}$ di tolak yang artinya ada perubahan IMT wanita usia subur setelah dilakukan senam aerobic. Senam aerobic efektif terhadap IMT normal wanita usia subur Di Desa Sentul Kabupaten Jombang.

Kata kunci : aerobic, indeks massa tubuh, wanita usia subur

\section{PENDAHULUAN}

Pada zaman sekarang ini seiring dengan
adanya perbaikan tingkat kehidupan dan
perkembangan teknologi telah mengakibatkan
perubahan gaya hidup. Salah satu gaya hidup yang
berkembang di Indonesia adalah gaya hidup
sedentarian. Gaya hidup sedentarian ditandai
dengan kurang aktif secara fisik. Hal ini bertolak
belakang dengan IMT Normal yang lebih banyak
dimiliki oleh individu yang mempunyai aktivitas fisik
yang tinggi (Yin T dan Seng Y, 2010). Ketidakaktifan fisik merupakan seseorang yang memiliki aktivitas fisik yang kurang atau tidak melakukan aktvitas fisik sama sekali. Hal ini dapat menimbulkan positive balance dimana ketidakseimbangan kalori yang masuk melalui makanan dan minuman dengan pembakaran kalori oleh aktivitas fisik tubuh yang mengakibatkan glukosa dan lemak darah meningkat serta berat badan naik. Hal ini mengakibatkan pembakaran energinya menjadi tidak lebih dari 1,5 kali pembakaran energi saat beristirahat.

Berdasarkan data Riset Kesehatan Dasar Kementrian Kesehatan Indonesia tahun 2007, saat 
ini $48,2 \%$ masyarakat berusia lebih dari 10 tahun kekurangan aktivitas fisik. Data dari Sunnybrook Health Sciences Center Kanada pada tahun 2010 menyatakan bahwa wanita tidak aktif pada usia 20 tahun namun menjadi aktif kembali pada usia 30 tahun dan 50 tahun. Data dari WHO menyebutkan di dunia pada tahun 2009 terdapat 60-80 persen populasi dewasa aktivitas fisik yang kurang. Ketidakaktifan fisik tersebut bila terjadi secara terus menerus dapat menyebabkan terjadinya obesitas dan juga berisiko mengalami penyakit kardiovaskular. Hal ini ditunjukkan pada orang yang memiliki aktivitas fisik yang kurang cenderung memiliki frekuensi jantung yang lebih tinggi yang mengakibatkan aktivitas otot jantung lebih tinggi pada saat kontraksi (Soeharto, 2004).

Dari berbagai macam pernyataan tersebut di atas maka senam aerobic menjadi salah satu cara meningkatkan aktivitas fisik, agar tercapai suatu kebugaran (physical fitness), yaitu keadaan badan sehat, mampu melakukan kerja sehari-hari tanpa kelelahan yang berarti dan masih memiliki sisa tenaga untuk menikmati waktu senggang atau kesenangan dan kegiatan tambahan yang mendadak (Busse \& Blazer, 2000). Oleh karena itu, penelitian tentang efektifitas senam aerobic terhadap keseimbangaan IMT perlu dilakukan. Tujuan dari penelitian ini adalah untuk mengetahui efektifitas senam aerobik pada wanita usia subur terhadap keseimbangan IMT Di Desa Sentul Kecamatan Ploso Kabupaten Jombang.

\section{METODE}

\section{Desain, tempat dan waktu}

Dalam penelitian ini jenis penelitian yang di gunakan adalah penelitian pra eksperimental dengan rancangan one-group pretest-posttest design (Notoadmodjo, 2012). Rancangan ini juga tidak ada kelompok pembanding (control), tetapi paling tidak sudah dilakukan observasi pertama (pre-test) yang memungkinkan peneliti dapat menguji perubahanperubahan yang terjadi setelah adanya eksperimen (program). Penelitian ini dilakukan di Desa Sentul Kabupaten Jombang. Penelitian ini dilaksanakan selama 4 minggu.

\section{Jumlah dan cara pengambilan subjek (untuk penelitian survei) atau}

Populasi pada penelitian ini adalah wanita usia subur yang mengikuti senam aerobik di Desa Sentul Kabupaten Jombang. Teknik sampling yang digunakan untuk mengambil subjek penelitian adalah total sampling. (Nursalam, 2016). Sampel pada penelitian ini adalah semua wanita usia subur yang mengikuti senam aerobic di Desa Sentul Kabupaten Jombang sebanyak 30 orang dengan cara melakukan pengamatan observasi langsung pada responden dengan menggunakan timbangan berat badan dan pengukur tinggi badan untuk penghitungan IMT responden sebelum dan sesudah dilakukan intervensi (Sismulyanto et al., 2017).

\section{HASIL}

Tabel 1

Tabulasi silang senam aerobic dan IMT setelah senam Desa Sentu

\begin{tabular}{ccccccccc}
\hline & \multicolumn{9}{c}{ Perubahan TD } & \multicolumn{2}{c}{ Total } \\
\cline { 2 - 9 } Senam & \multicolumn{1}{c}{ Underweight } & \multicolumn{2}{c}{ Normal } & Overweight & & \\
\cline { 2 - 9 } & $\mathrm{F}$ & $\%$ & $\mathrm{~F}$ & $\%$ & $\mathrm{~F}$ & $\%$ & $\mathrm{~F}$ & $\%$ \\
\hline Senam & 0 & 0 & 18 & 60 & 12 & 40 & 30 & 100 \\
Tidak & 0 & 0 & 0 & 0 & 0 & 0 & 0 & 0 \\
senam & & & & & & & & \\
\hline Total & 0 & 0 & 18 & 60 & 12 & 40 & 30 & 100 \\
\hline
\end{tabular}

Tabel 2

Hasil uji wilcoxon perubahan IMT dengan menggunakan senam aerobic Desa Sentul

\begin{tabular}{cc}
\hline \multicolumn{2}{c}{ Uji Wilcoxon } \\
\hline$Z$ & $-3,742$ \\
$p$-value & 0,000 \\
$\mathrm{~N}$ & 30 \\
\hline
\end{tabular}

Hasil pengambilan data tabulasi silang didapatkan Berdasarkan tabel 1 menunjukkan bahwa sebagian besar $(60 \%)$ dari 30 responden yang mengikuti senam aerobic 18 diantaranya memiliki IMT normal. Dari hasil perhitungan menggunakan aplikasi SPSS pada tabel 2 didapatkan Z hitung $3,742>Z$ tabel $-1,96$. Nilai asymp sig.(2 failed) atau nilai probabilitas $p=(0,000)$ lebih rendah dari standart signifikan $\alpha=0,05$ atau $(p<a)$ yang berarti $\mathrm{H}_{0}$ di tolak yang artinya ada perubahan IMT wanita usia subur setelah dilakukan senam aerobic di Desa Sentul.

\section{PEMBAHASAN}

Dalam penelitian ini terjadi perubahan IMT setelah dilakukan perlakuan senam aerobic pada wanita usia subur. Berdasarkan Tabel 4.5 dapat diketahui bahwa rata-rata IMT wanita usia subur setelah mengikuti senam aerobic menunjukkan bahwa hampir seluruhnya 18 (60\%) responden yang masuk dalam kategori IMT normal $(18,5-22,9)$.

Indeks massa tubuh (IMT) merupakan salah satu indikator yang dapat dipercayai untuk mengukur lemak tubuh. Walau bagaimanapun, terdapat beberapa kekurangan dan kelebihan dalam mnggunakan IMT sebagai indikator pengukuran lemak tubuh. Kekurangan indeks massa tubuh pada olahragawan: tidak akurat pada olahragawan (terutama atlet bina) yang cenderung berada pada kategori obesitas dalam IMT disebabkan mereka mempunyai massa otot yang berlebihan walaupun 
presentase lemah tubuh mereka dalam kadar yang rendah. Sedangkan dalam pengukuran berdasarkan berat badan dan tinggi badan, kenaikan nilai IMT adalah disebabkan oleh lemak tubuh.

Dalam penelitian ini dilakukan dengan memberikan perlakuan senam aerobic selama 4 minggu dengan frekuensi 4 kali didapatkan hasil berdasarkan tabel 4.6 menunjukkan bahwa sebagian besar $(60 \%)$ dari 30 responden yang mengikuti senam aerobic 18 diantaranya memiliki IMT normal. Untuk mengetahui perubahan IMT dengan menggunakan senam aerobic maka dilakukan analisa data dengan uji statistic menggunakan uji Wilcoxon Signed Ranks Test. Hasil Wilcoxon Signed Ranks IMT sebelum dan sesudah dilakukan perlakuan didapatkan nilai $p$ value sebesar $0,000<$ 0,05 maka Ho ditolak dan $\mathrm{H} 1$ diterima artinya senam aerobic efektif dalam memperngaruhi IMT wanita usia subur Desa Sentul Kecamatan Tembelang Kabupaten Jombang.

Berdasarkan uraian diatas dengan hasil $p$ value yang rendah dapat disimpulkan bahwa perubahan IMT responden bukan hanya dipengaruhi oleh senam aerobic yang diberikan oleh peneliti tetapi juga dipengaruhi oleh usia dan kebiasaan hidup responden seperti mengkonsumsi, alkohol,kopi, makanan berlemak, rokok, garam serta olahraga diamana meski senam aerobic mampu menormalkan IMT tetapi untuk mencapai hasil yang maksimal diperlukan juga kebiasaan hidup yang baik dari responden.

Indeks massa tubuh (IMT) adalah nilai yang diambil dari perhitungan antara berat badan (BB) dan tinggi badan (TB) seseorang. IMT dipercayai dapat menjadi indikator atau mengambarkan kadar adipositas dalam tubuh seseorang. IMT tidak mengukur lemak tubuh secara langsung, tetapi penelitian menunjukkan bahwa IMT berkorelasi dengan pengukuran secara langsung lemak tubuh seperti underwater weighing dan dual energy $x$-ray absorbtiometry (Mei et al., 2002).

IMT (Indeks Massa Tubuh) dapat dipengaruhi dengan senam aerobic, tapi selain itu perubahan IMT wanita usia subur juga dapat dipengaruhi oleh makanan, pola hidup dan konsumsi kopi/ alcohol. Oleh karena itu jika ingin mendapatkan IMT yang ideal harus mengurangi konsumsi makanan yang mengandung lemak, menghindari konsumsi kopi/ alcohol dan berolahraga secara teratur.

\section{KESIMPULAN}

Berdasarkan hasil penelitian diperoleh kesimpulan sebagai berikut : Sebelum diberikan senam aerobic sebagian besar IMT responden termasuk dalam katergori Overweight. Setelah diberikan senam aerobic, IMT responden mengalami perubahan yang sebelumnya IMT dalam kategori overweight menjadi normal, namun ada beberapa yang tetap tidak mengalami perubahan IMT. Senam aerobic efektif terhadap IMT normal wanita usia subur Di Desa Sentul Kabupaten Jombang.

\section{SARAN}

1. Bagi peneliti selanjutnya

Bagi peneliti selanjutnya, di sarankan untuk mengembangkan penelitian tentang faktor-faktor lain yang mempengaruhi perubahan IMT selain senam aerobic. Dan untuk penelitian dengan senam selanjutnya dilakukan lebih lama untuk hasil yang lebih signifikan.

\section{Bagi responden}

Perlu Adanya control dan terapi yang teratur serta perbanyak dosis \& frekuensi yang diulang yang memungkingkan dapat membantu untuk menormalkan IMT dan memperkecil resiko terjadi obesitas yang lebih berat serta di harapkan dapat menghindari faktor-faktor penyebab obesitas.

\section{Bagi tempat penelitian}

Diharapkan hasil penelitian ini dapat dijadikan sebagai bahan masukan bagi petugas kesehatan dan dapat menjadi bahan pertimbanagan dalam meningkatkan kebugaran jasmani wanita usia subur.

4. Bagi tenaga kesehatan

Agar petugas kesehatan lebih
memperhatikan kegiatan yang bisa
meningkatkan kesehatan masyarakat dengan
informasi yang benar dan meningkatkan teknis
komunikasi yang efektif antara tenaga kesehatan
dan masyarakat, pendekatan personal, dan
pemberian konseling yang efektif.

\section{UCAPAN TERIMAKASIH}

Terimakasih penulis sampaikan pada semua pihak yang sudah terlibat dalam penelitian ini, terutama anggota senam aerobic Desa Sentul Kabupaten Jombang yang telah bersedia menjadi responden dalam penelitian ini. Kepala Desa Sentul yang telah memberikan ijin penulis hingga dapat terselesaikannya penelitian ini.

\section{DAFTAR PUSTAKA}

Alligood, M. R. (2017). Pakar Teori Keperawatan. Nursing Theorist and their Work. (8th ed.). United States of America.

Hidayat A. A., (2010). Metode Penelitian Kesehatan Paradigma Kuantitatif. 
Centers of Disease Control and Prevention (CDC). (2009). Assessing Your Weight: About BMI for Adult. Available from: http://cdc.gov/healthyweight/assessing/bmi/adult_bmi/index.html

Centre for Obesity Research and Education. (2007). Body Mass Index: BMI Calculator. Available from: http://www.core.monash.org/bmi.html

Depkes RI. (2003). Survey Indeks Masa Tubuh (IMT) Pengumpulan Status Gizi Orang Dewasa Berdasarkan IMT. Jakarta: Direktorat Bina Gizi Masyarakat

Depkes RI. (2011). Karakteristik Berat Badan dengan IMT Indonesia. Jakarta: Depkes RI.

Mei, Z., Grummer-Strawn, L. M., Pietrobelli, A., Goulding, A., Goran, M. I., Dietz, W. H. (2002). Validity of body mass index compared with other body-composition screening indexes for the assessment of body fatness in children and adolescents. American Journal of Clinical Nutrition. 75(6), 978-85.

Nursalam. (2016). Metodologi penelitian ilmu keperawatan. Jakarta: Salemba Medika.

Notoatmodjo, S. (2012). Metodologi Penelitian Kesehatan. Jakarta: Rineka Cipta.

Sismulyanto, Priastana, I. K. A., Basuki, H. O., Silvanasari, I. A., Melizza, N., Pitaloka, D. Januarti, L. F. (2017). Pengkajian Keperawatan Komunitas berdasarkan Pendekatan Empat Metode Pengkajian: Survey, Asset Inventory, FGD, dan Community Meeting. Surabaya: Fakultas Keperawatan Universitas Airlangga.

WHO. (2004). Global Database On Body Mass Index. Available from: http//www.who.int/bmi/index. 